\title{
COVID-19 Pandemic - New Stage of Social Digital Transformation
}

\author{
O. M. Mikhaylenok ${ }^{1}$, G. A.Malysheva ${ }^{1}$
}

\begin{tabular}{lr}
\hline 1. Institute of Sociology FCTAS RAS, 24/35 Krzhizhanovskogo Street, Moscow 117218, Russian Federation \\
\hline DOI: $10.18255 / 2412-6519-2021-1-28-39$ & Research Article \\
Full text in Russian
\end{tabular}

The authors focus on the problems of social digital modernization, with COVID-19 pandemic being another stage in it. The pandemic crisis is considered by them as one of the global network threats of a new type. It is emphasized that amid the administrative restriction of physical contacts, digital networks fully unlock their communication potential and demonstrate the capacities of online formats of information consumption. At the same time, the network nature of virtual communication determines the specifics of social response to coronavirus crisis challenges which is expressed in infodemiological contamination of the media space. The context of the pandemic boosts innovative technological developments in different areas of human activity and encourages the spread of various useful online social practices, however, at the same time it allows assessing the degree and scope of risks connected with the forced digitalization of the sphere of the humanities. A new digital stratification of society, technologization and dehumanization of the social fabric, blurring the borders of human life privacy pervaded with different forms of external digital control are becoming real threats. The question of acceptable limits of state digital interference in civil rights and freedoms and, generally, the question of preserving the fundamental democratic values amid the global digital transformation are becoming relevant. The authors discuss the reinterpretation of the social contract main parameters at the new stage of social and technological development, also touching upon the project of its modification in the globalist sense, and make a conclusion about the need to focus on the cultural matrix and the existing social values when accomplishing the objectives of its digital reformatting.

Keywords: COVID-19 pandemic; digital transformation; networkization of society; social media; infodemic; dehumanization of communication space; digital inequality; digital control

INFORMATION ABOUT THE AUTHORS

$$
\begin{array}{r|l}
\begin{array}{r}
\text { Mikhaylenok, Oleg M. } \\
\text { (correspondence author) }
\end{array} & \begin{array}{l}
\text { E-mail: m-oleg-m@yandex.ru } \\
\text { Doc. Sc. (Politics), Professor }
\end{array} \\
\text { Malysheva, Galina A. } & \begin{array}{l}
\text { E-mail: lamaga2007@yandex.ru } \\
\text { Researcher }
\end{array}
\end{array}
$$

For citation: Mikhaylenok O. M., Malysheva G. A. COVID-19 Pandemic - new stage of social digital transformation // Social'nye i gumanitarnye znanija. 2021. Vol. 7, No 1. P. 28-39. (in Russ.)

(C) Mikhaylenok O. M., Malysheva G. A., 2021

This is an open access article under the CC BY license (https://creativecommons.org/licenses/by/4.0/) 


\title{
Пандемия COVID-19 - новый этап цифровой трансформации общества
}

\author{
О. М. Михайленок ${ }^{1}$, Г. А. Малышева ${ }^{1}$
}

1ЦЦентр политологии и политической социологии, Институт социологии ФНИСЦ РАН, ул. Кржижановского, 24/35, корп. 5, Москва, 117218, Российская Федерация

DOI: $10.18255 / 2412-6519-2021-1-28-39$

УДК 316.422

Научная статья

Полный текст на русском языке

Внимание авторов сосредоточено на проблематике цифровой модернизации социума, очередным этапом которой они считают пандемию коронавируса COVID-19. Пандемический кризис рассматривается ими как одна из глобальных сетевых угроз нового типа. Подчеркивается, что в условиях административного ограничения физических контактов цифровые сети в полной мере раскрывают свой коммуникационный потенциал и демонстрируют возможности онлайновых форматов информационного потребления. В то же время сетевой характер виртуальной коммуникации обусловливает специфику социального реагирования на вызовы коронакризиса, выражающуюся в инфодемическом заражении медийного пространства. Контекст пандемии придает ускорение инновационным технологическим разработкам в различных областях человеческой деятельности и служит распространению многих полезных онлайновых социальных практик, но одновременно позволяет оценить степень и масштабы рисков, сопряженных с форсированной цифровизацией гуманитарной сферы. Становятся реальными угрозы нового цифрового расслоения общества, технологизации и дегуманизации социальной ткани, размывания границ приватности человеческой жизни, пронизанной разнообразными формами внешнего цифрового контроля. Актуализируется вопрос о допустимых пределах цифрового вмешательства государства в область гражданских прав и свобод и в более общем плане о сохранении фундаментальных ценностей демократии в условиях глобального цифрового перехода. Авторы рассуждают на тему переосмысления основных параметров общественного договора на новом этапе социально-технологического развития, затрагивая, в частности, проект его модификации в глобалистском ключе, и приходят к выводу о необходимости ориентации на культурную матрицу и сложившийся ценностный уклад общества при реализации задач его цифрового переформатирования.

Ключевые слова: пандемия COVID-19; цифровая трансформация; сетевизация общества; социальные медиа; инфодемия; дегуманизация коммуникативного пространства; цифровое неравенство; цифровой контроль

ИНФОРМАЦИЯ ОБ АВТОРАХ

Михайленок, Олег Михайлович (автор для корреспонденции)

E-mail: m-oleg-m@yandex.ru

Доктор политических наук, профессор, руководитель отдела исследования социально-политических отношений

Малышева, Галина Анатольевна | E-mail: lamaga2007@yandex.ru

Научный сотрудник

Для цитирования: Михайленок О. М., Малышева Г. А. Пандемия COVID-19 - новый этап цифровой трансформации общества // Социальные и гуманитарные знания. 2021. Том 7, № 1. С. 28-39.

(C) Михайленок О. М., Малышева Г. А., 2021

Статья открытого доступа под лицензией СС BY (https://creativecommons.org/licenses/by/4.0/) 


\section{Введение}

Прошедший 2020-й год стал годом больших потрясений во всем в мире, и одним из главных факторов перемен, или, как теперь говорят, их триггером, безусловно, явилась глобальная пандемия вируса COVID-19. Коронавирусный социальный опыт уникален, происходящее во многом не имеет прецедентов, а проблемные узлы, которые обнаруживаются по мере развития кризиса, не только отличаются слабой изученностью и принципиальной новизной, но и зачастую лежат на стыке различных, весьма далеких друг от друга областей научного знания. Все это заставляет исследователей выходить за рамки привычных подходов к их осмыслению.

В этой связи мы должны подчеркнуть два существенных момента. Во-первых, пандемия нам видится как сетевое социальное явление, и ее роль и значение рассматриваются нами через призму сетевых общественных процессов. Во-вторых, анализ глобального пандемического кризиса важен для нас с точки зрения цифровой трансформации социума. Иными словами, мы трактуем глобальный пандемический кризис как качественно новый этап всеобъемлющей социальной цифровизации. Последствия коронакризиса и сопряженные с ним вызовы и риски оцениваются нами с учетом указанных факторов.

Цифровая сетевизация является одной из приоритетных характеристик общества на современной стадии социально-технологического развития. Имплантация в гуманитарную ткань новейших цифровых технологий видоизменяет сетевые свойства социума, проявления которых отмечаются во всех сферах общественного бытия, в его физических и виртуальных реалиях. Подвергаясь оцифровке, социальная жизнь гибридизируется, приобретает конвергентные черты, а человек все больше погружается в сетевые «цифромиры», которые становятся «не только местом досуга и общения, но и местом воспитания ценностей» $[1$, с. 51,53$]$.

Пандемия коронавируса началась на активной фазе цифрового социально-технологического перехода. За прошедшие месяцы получили ускорение многие тренды цифрового развития, непосредственно связанные с ковид-эпидемией. На наших глазах вырабатываются новые привычки и паттерны социального поведения, постоянно возрастает потребность людей в защитных и профилактических мерах, которые базируются на продвинутых технологических решениях.

В то же время формирование цифровых социальных практик происходит в ситуации «техногуманитарного дисбаланса», когда общество «не успевает договариваться о правилах использования новых технологий». В результате усугубляется разрыв между технологическим оптимизмом, с одной стороны, и ростом опасений относительно социальных последствий технологической экспансии в гуманитарную сферу - с другой [2, с. 35]. Одна из главных опасностей ускоренного цифрового перехода видится в «глобальной унификации форм и способов бытия», в возможном торжестве технократической идеологии, которая способна нивелировать «все многообразие культур, представлений и жизненных укладов современного мира» [3, с. 300].

Сетевая природа пандемии COVID-19 определяется не только виртуализацией коронакризисной повседневности и ее коммуникационного наполнения. Сама пандемия, согласно существующему мнению, это своего рода «живая сеть», которая «может принимать самые неожиданные формы в зависимости от изменяющихся условий» и характеризуется как «круговорот социальных взаимосвязей» [4, р. 27]. Не подпадая 
под устоявшиеся схемы, коронакризис служит стресс-тестом для людей, сообществ, организаций, управленческих структур и правительств по всему миру. В частности, сопровождающий пандемию «информационный шторм» высвечивает новые уязвимости онлайновых форм массовой коммуникации, чем ставит под сомнение их исторически-позитивную роль - из техносоциального блага они становятся дополнительным фактором риска для человека.

\section{Информационно-сетевые вызовы пандемии}

Пандемия эпохи цифрового общества приобретает специфику, в силу которой она существенно отличается от масштабных эпидемий «классического» типа. Эта специфика в первую очередь связана с ее технологическими и информационно-сетевыми аспектами.

В условиях действия карантинных мер и ограничения физических контактов виртуальные сети становятся главным инструментом межличностной и групповой коммуникации, а также основой для онлайн-форматирования трудовой деятельности, образовательного процесса и сферы услуг. Отмечается, что за год пандемического кризиса в России возросла доля тех, кто пользуется возможностями интернета для общения с друзьями, знакомыми и родственниками (90\%), а также для получения новостей (83 \%) и разного рода развлекательного контента (73 \%) [5].

Виртуализация трудовой деятельности и досуга граждан способствует совершенствованию их цифровых навыков и компетенций. Одновременно коронакризис усиливает и наиболее релевантные тренды в структуре медиапотребления россиян. Главным из них является снижение интереса к традиционным СМИ и перемещение потребительских практик в сферу цифровых социальных медиа: в соцсети интернета, публичные каналы и чаты мессенджеров, блоги, форумы и т. д. Интернет успешно конкурирует с телевидением, самым популярным и общедоступным средством массовой информации, приверженцами которого остаются в основном люди старшего поколения, хотя и они постепенно осваивают онлайновый сетевой мир. Молодежь же практически полностью погружена в виртуальное медийное пространство [6].

Трансформируются каналы потребления как новостной, так и развлекательной информации: их классические формы дополняются, а в условиях самоизоляции и вытесняются онлайновыми цифросетевыми. Традиционные медиа, следуя запросам аудитории, дублируют свой информ-контент на социальных платформах интернета. «Заменой» телевидению становятся медиахостинги Instagram, Youtube и TikTok, а позиции наиболее популярного канала-«новостника» уверенно завоевывает мессенджер Telegram [7].

Являясь средством публичной коммуникации, онлайновые сети способствуют социальной солидаризации граждан, служат для обмена стратегиями выживания в форс-мажорных условиях, взаимной моральной и психологической поддержки. Вместе с тем в контексте пандемии они выполняют и специфическую информационно-коммуникативную функцию, выступая в качестве социально-технологической базы массового инфодемического заражения.

Инфодемией принято называть информационное перенасыщение медийного рынка, которое сопровождается масштабным распространением фейкового (непроверенного, недостоверного и откровенно лживого) контента на коронавирусную тематику. Мы привязываем ее к пандемии COVID-19, так как впервые в полной мере 
столкнулись с данным феноменом именно в связи с мировой эпидемией коронавируса. Но, собственно, инфодемическая реакция как особый режим функционирования цифровой коммуникационной сферы может возникнуть в ответ на любую глобальную угрозу нового, малоизученного типа. Веб-сети в силу своей природы, поскольку они являются средоточием пользовательского контента, свободного от требований профессионального фактчекинга, формируют наиболее «дружественную» среду для развития инфодемии.

В условиях кризиса инфодемический медийный фон катализирует общественную тревожность, провоцирует иррациональное социальное поведение, подрывает доверие к властной информационной и административной повестке и служит фактором политической дестабилизации.

Инфодемию типологизируют как с точки зрения ее содержательной части, так и в зависимости от моделей сетевой дистрибуции. Как показывают исследования, лишь часть инфодемического контента является целенаправленно сфабрикованным материалом, основной же его массив составляет текущая интернет-информация, переформатированная и «пересобранная» таким образом, что перестает быть достоверной - своего рода цифросетевое «сарафанное радио». Выделяют нисходящий тип распространения инфодемии, по направлению от лидеров политической и медийной сфер в массы, и восходящий ее тип, когда недостоверный контент инфодемического характера зарождается в среде рядовых пользователей социальных медиа [8].

Обращается внимание также на то, что ключевые игроки рынка цифровых коммуникационных технологий, крупнейшие IT-корпорации, под чьим контролем находятся основные мировые структуры интернета, хотя и предпринимают некоторые шаги, но тем не менее делают недостаточно для решительного противодействия инфодемии в виртуальных сетях. Данный факт воспринимается как свидетельство того, что достижение подобной цели не входит в круг их первоочередных экономических и иных интересов [9].

В этой связи примечательно, что веб-информация инфодемического типа носит черты манипулятивного контента и может быть использована для решения политических задач. Она может применяться в реализации стратегий компьютерной пропаганды, одной из главных составляющих современного арсенала цифровых политических технологий. В частности, в ее распространении широко задействованы социальные и политические боты - автоматизированные искусственные сущности интернета, которые образуют значительный сегмент цифросетевого медийного пространства [10]. С данной точки зрения инфодемия может рассматриваться не только как часть медийного сопровождения глобального биосоциального кризиса, но и как инструмент информационных войн.

Важно помнить, что феномен инфодемии и оценка ее внутриполитических рисков увязываются с уровнем институционального доверия в обществе [11, с. 72, 74]. Несмотря на то, что его показатели в России традиционно невысоки, за исключением доверия к президентской власти [12, с. 34-36], опыт первой и второй волн пандемии свидетельствует: в нашей стране удалось избежать наиболее тяжелых социальных последствий сетевого инфодемического заражения - массовой паники и серьезного общественного недовольства.

Хотя антикризисный курс руководства страны не лишен просчетов и недоработок, россияне в целом с пониманием относятся к действиям властей. Не менее двух третей из них в той или иной степени выражают доверие официальной информации 
на тему коронавируса [13], примерно такая же доля граждан высказывает одобрение принятым властями мерам по борьбе с пандемией [14]. Мнение о том, что Россия прошла испытания коронакризиса легче, чем большинство других стран, оказалось наиболее распространенным среди наших сограждан, а в будущее они смотрят с умеренным оптимизмом [15].

Таким образом, судя по динамике социальных настроений, тезис о том, что информационный фон пандемии оказывает деморализующее и дестабилизирующее влияние на общество, на наш взгляд, к России применим в гораздо меньшей степени, чем ко многим другим государствам, в том числе к странам-лидерам мирового развития. Причин тому несколько.

Преобладающей характеристикой российского социума остается этатистский, государственно-ориентированный менталитет, а российские власти, со своей стороны, по-прежнему чутко улавливают социальный запрос на сильное государство и встраивают его в формирование управленческих стратегий. Пандемический опыт показал, что в России ресурс общественного доверия властям оказался далеко не исчерпанным. Доверие, пусть и в значительной степени персонифицированное, продолжает выполнять стабилизирующую социальную функцию. Кроме того, антикризисная практика свидетельствует и о сохранении достаточно высокого запаса институциональной надежности в сфере отечественного здравоохранения.

Немаловажно также учитывать, что наши сограждане обладают высокой резистентностью ко всякого рода кризисам и потрясениям. Российское общество закалено годами перестройки и турбулентностью постсоветского транзита, что обусловливает его стрессоустойчивость и способность не просто адаптироваться к трудностям, но и успешно преодолевать их.

К тому же характеру и менталитету россиян свойственны разнообразные механизмы социально-психологической защиты. К ним, в частности, можно отнести способность солидаризироваться в экстремальных ситуациях [16], а также позитивный багаж народной смеховой культуры, которая органично вошла в современную коммуникативно-технологическую среду и в случае пандемии помогает использовать юмор как лекарство от стресса [17] - своего рода сетевую «карнавализацию» кризиса. Она имеет множество проявлений, в том числе онлайновый меметический контент, в шутливой форме интерпретирующий события и факты коронавирусного периода, иронический ковидный «новояз», коллективные развлекательные сетевые акции (флешмобы, челленджи) и многое другое.

\section{Риски цифровых решений}

Уже говорилось о том, что глобальная эпидемия COVID-19 в нашем понимании - социотехнологический феномен и рассматривается в качестве очередного этапа цифровой трансформации общества. Контекст пандемии позволил проявить себя многим достижениям Четвертой промышленной революции. Целый ряд передовых технологических практик, о которых ранее речь велась на уровне прогнозов и предположений, за время кризиса стал частью нашей повседневной реальности.

В условиях ограничений и борьбы с вирусным заражением произошла форсированная цифровизация различных областей человеческой деятельности. В первую очередь она обусловлена продвижением дистанционных моделей и форм социального, производственного и корпоративного взаимодействия. Поиск бесконтактных 
решений повысил востребованность многих цифровых трендов, включая мессенджеры и сервисы для видеоконференций (Zoom, Skype, Microsoft Teams, а также популярные среди азиатских пользователей WeChat и Ding), интерактивные программы онлайн-обучения, платформы и приложения электронной торговли. Повсеместно распространяются технологии отслеживания социальных контактов и облачного хранения данных, на основе которых создаются интегрированные системы мониторинга на общенациональном уровне.

Получили новый импульс к развитию такие цифровые отрасли, как «интернет вещей», искусственный интеллект, автоматизация и робототехника. Машинные алгоритмы находят применение в диагностике и разработке вакцин, интеллектуальные устройства (умные термометры, AR-шлемы, системы распознавания лиц и считывания QR-кодов) становятся инструментами борьбы с COVID-19 в общественных местах. Роботам и беспилотным аппаратам доверяется часть функций санитарных служб и медицинского персонала (уборка и дезинфекция помещений и улиц, доставка еды и медикаментов, ряд обязанностей по уходу за пациентами клиник).

Ускоренная глобальной эпидемией цифровая трансформация вновь и особенно остро ставит вопрос об оценке ее социальных и политических рисков.

Прежде всего она непосредственным образом связана с экзистенциальной проблемой цифрового суверенитета. Большинство цифровых решений, включая технологии сбора данных и массовой сетевой коммуникации, «предлагаются и поддерживаются достаточно небольшим числом крупнейших платформ», которые принадлежат главным образом компаниям-резидентам США [18, с. 5]. Иначе говоря, контрольно-управленческие центры критически важной части цифросетевой инфраструктуры находятся за пределами нашей страны.

Не будем забывать, что технологии разрабатываются людьми и в силу этого «несут в себе отражение целей и убеждений» своих создателей. Они отображают те или иные «социальные установки и интересы», «разные культуры и типы ценностей», т. е. обладают определенным политическим наполнением [19, с. 50-52]. Следовательно, в условиях биосоциального или любого другого масштабного кризиса работа ключевых технологических платформ, без которых невозможно стабильное функционирование общества, находится в зависимости от таких факторов, как политические интересы тех или иных глобальных игроков и их видение политической целесообразности.

Далее, цифровизация, не являясь панацеей от традиционных общественных неравенств, продуцирует новые их разновидности. Социальный разрыв в цифровой среде, возникающий в связи с различными возможностями доступа к технологиям и средствам коммуникации, обостряется в условиях карантина и самоизоляции. Диспропорции в овладении цифровыми навыками и неравномерность технического обеспечения обусловливают неравноправие граждан с точки зрения доступности дистанционных форм работы и учебы, а также разного рода онлайновых сервисов, включая широкий спектр цифровых госуслуг. В наиболее уязвимом положении оказываются люди старшего возраста, что дает основания говорить о феномене медиаинвалидности [20] определенных страт населения.

Кроме того, несанкционированное использование полученных в ходе ковидмониторинга цифровых персональных данных создает почву для возникновения новых, профайлинговых форм дискриминации и стигматизации граждан и социальных 
групп по целому ряду признаков [21]. К ним относятся: наличие у человека коронавирусной инфекции, постоянные контакты, в том числе профессиональные, с заболевшими людьми, этническая принадлежность, «подозрительная» с точки зрения динамики распространения COVID-19, вовлеченность в миграционные потоки и т. д.

Среди наиболее серьезных антропологических рисков цифрового перехода необходимо указать и дегуманизацию социально-коммуникативного пространства. Позитивный потенциал дигитализации ставится под сомнение в случаях, когда общество пытается заместить традиционные «живые» взаимодействия их оцифрованным суррогатом. Надо заметить, что единого взгляда на эту проблему нет. Одни считают, что технологизация социального и культурного обмена приводит к его выхолащиванию и примитивизации [3], другие, напротив, убеждены в преимуществах цифровых технологий, которые, по их мнению, расширяют границы культурного потребления человечества [22].

Технологическая экспансия в гуманитарную сферу нуждается в скрупулезном анализе ее эффектов. В частности, роботизации и применению искусственного интеллекта в медицине сопутствует утрата живого контакта врача с пациентом и «подмена человеческого сочувствия его симулякром» [23, с. 99]. Всепроникающий технологизм вымывает гуманитарную компоненту коммуникации, поскольку нейронная сеть «рассматривает» человека не как живое существо, а как тоже своего рода машину. Межличностные связи, реализуемые через цифросетевое пространство, становятся все более технологически опосредованными, что накладывает отпечаток на механизмы передачи социального опыта и трансляции культурных ценностей.

Наконец, целый комплекс проблем связан с кибербезопасностью, соблюдением цифровых прав граждан и перспективой ужесточения цифрового контроля. Кризис коронавируса спровоцировал бурное развитие технологий по отслеживанию социальных контактов и геолокационных данных через переносные цифровые устройства под предлогом защиты общественных интересов и безопасности, что, в свою очередь, ставит вопрос о допустимых границах административного вторжения в приватную жизнь и о контурах согласия по поводу контролирующих функций государства.

Заметим, что россияне в коронавирусный период, подобно большинству населения других стран, в целом оказались готовы мириться с частичным поражением в правах ради борьбы с распространением инфекции. Они высказываются в поддержку практически всех ограничительных мер властей, за исключением высоких штрафов и уголовного преследования за нарушение карантина. При этом так называемыми ковид-диссидентскими настроениями охвачено подавляющее меньшинство населения России [24].

\section{Перезагрузка общественного договора}

Очевидно, что пандемический контекст определяет существенные сдвиги в общественном видении лояльности и социально ответственного поведения. Одним из главных условий ковид-конформизма граждан называется их уверенность в том, что собранные в ходе мониторинга персональные данные будут использованы исключительно в заявленных целях, а государство обеспечит неприкосновенность этого ценного информационного ресурса $[18$, с. 12]. В данной связи показательна специфика 
гражданской идентичности в странах и обществах с различной культурно-исторической традицией, характеризуемых в рамках отологической дихотомии как авторитарные и демократические, либо как коллективистские и индивидуалистические [25].

Неодинаковость культурных моделей реагирования на пандемический кризис определяется в том числе степенью дистанцирования граждан от власти и готовностью общества к интенсификации и мультипликации форм цифрового надзора. Так, разделение европейской и азиатской социальной и политической культуры [26] обусловливает два разных подхода к применению цифровых технологий в антикризисном управлении. Если в странах Азии отмечается «коллективистский дух», который выражается в поддержке правительственных мер и добровольном соблюдении условий карантина, то в западных демократиях приоритетными становятся вопросы соблюдения прав человека и основ правового государства [27].

Пандемия COVID-19 продемонстрировала масштаб цифровой трансформации и глубину ее проникновения в гуманитарную сферу. Вызванные цифровизацией изменения настолько радикальны, что людям приходится переосмысливать прежние правила общественного сосуществования. Иными словами, новый этап цифровой трансформации социума подразумевает и пересмотр условий общественного договора.

Для так называемых «свободных» обществ на нынешней стадии социальнотехнологического развития становится в высшей степени актуальным вопрос о том, как в условиях всепроникающего цифрового контроля обеспечить фундаментальные - в их традиционном понимании - ценности демократии и избежать сценария, который ведет к торжеству цифрового тоталитаризма. Неразрешимость подобной дилеммы подталкивает к поиску решений, которые можно трактовать как доказательство прогрессирующей эрозии видения самой сущности демократического устройства.

В частности, в резонансном проекте модернизации, или цифровой «перезагрузки» общественного договора, запущенном от лица Всемирного экономического форума, предлагается выстраивать согласие граждан и управляющих элит за счет выработки некоего глобального модуса политики, направленной на удовлетворение базовых потребностей социума, право на реализацию которой изымается из ведения национального государства и делегируется наднациональным структурам - самопровозглашенным лидерам и главным бенефициарам мировой дигитальной перестройки, якобы способной уберечь человечество от «хаоса многополярности» $[4$, p. $79-80,82,86,90]$.

Тотальный цифровой контроль при этом преподносится как допустимая мера обеспечения безопасности, которую общество рано или поздно будет вынуждено признать «нормальной», в силу чего она станет одним из компонентов обновленного социального контракта [Там же. С. $77,118,126]$. По сути, этот глобалистский сценарий пост-ковидной цифровой трансформации, завуалированный фарисейскими лозунгами заботы о всеобщем благе и интересах грядущих поколений, предусматривает повсеместное «ползучее» проникновение идеологизированного технократизма и в конечном итоге ведет к обезличиванию социокультурного ландшафта современного мира.

Между тем многообразие культурно-исторических матриц, на наш взгляд, служит одним из основных аргументов в пользу того, что цифровизация не является 
универсальным (и универсалистским) проектом и что в разных странах мира цифровое общество может формироваться на основе национальных моделей развития, «с учетом собственных традиций и этических норм» [28, с. 17]. Главными субъектами социально-технологической модернизации в этом случае выступают национальное государство и национально-ориентированные элиты. В России пандемический опыт показал, что общественный консенсус по-прежнему базируется главным образом на запросе на сильное государство, поэтому властным кругам потребуется максимум управленческого искусства, чтобы пройти окно возможностей цифровой трансформации при сохранении социального мира и стабильности.

\section{Заключение}

Глобальная пандемия COVID-19 видится как социетальное явление, воздействие которого на общественное бытие носит комплексный и многоуровневый характер. Не вызывает сомнения, что едва ли не главным социальным эффектом эпидемии коронавируса явились виртуализация и цифровое переформатирование многих сфер человеческой жизнедеятельности, поэтому мы оцениваем произошедшие за время пандемического кризиса сдвиги, исходя из логики развития цифросетевых процессов.

Именно информационно-сетевые характеристики общества дают возможность в полной мере оценить масштаб и динамику нового этапа цифрового социального перехода. Мы можем констатировать, что в условиях пандемических ограничений онлайновые сети продемонстрировали свою незаменимость в качестве инструмента социальной коммуникации, а также как технологическая база наиболее перспективных форматов медийного потребления. Они же служат и главным проводником инфодемической реакции социума на новые угрозы глобального порядка.

Опыт коронавирусного периода способствовал раскрытию потенциала многих цифровых решений, но в то же время со всей очевидностью показал, насколько рискованным и неоднозначным может быть процесс внедрения инноваций в социальную ткань и насколько далеко идущими могут быть его культурные и политические последствия. Пандемия заставила общество вплотную столкнуться с такими проблемами, как прогрессирующая технологизация сознания, дегуманизация социальных практик, усугубление цифровых форм неравенства, а также с многочисленными вызовами, которые обусловлены ростом цифрового вторжения в личное пространство человека и в область гражданских прав и свобод.

Можно утверждать, что ускоренная пандемией цифровая трансформация сформировала новую социальную повестку, которая повлечет за собой корректирование политических стратегий на глобальном и национальном уровнях, а также обновление подходов к параметрам общественного договора, с тем чтобы адаптировать его к требованиям очередного этапа мирового техносоциального развития.

\section{Ссылки / References}

1. Аршинов В. И., Буданов В. Г. Онтологии и риски цифрового техноуклада: к вопросу о представлении социотехнического ландшафта // Сложность. Разум. Постнеклассика. 2019. № 2. C. 51-60. DOI: 10.12737/article_5d4834d5af2985.35191802 
2. Журавлев А. Л., Нестик Т. А. Социально-психологические последствия внедрения новых технологий: перспективные направления исследований // Психологический журнал. 2019. T. 40. № 5. C. 35-47. DOI: 10.31857/S020595920006074-7

3. Яницкий О. Н. Четвертая научно-техническая революция и культура в контексте пандемии // Власть. 2020. Том 28. № 5. C. 298-304. DOI: 10.31171/vlast.v28i5.7620

4. Schwab K., Malleret T. COVID-19: The Great Reset. World Economic Forum. Geneva, 2020. $212 \mathrm{p}$.

5. Жизнь онлайн: потребление, пользование, развлечения. Аналитический обзор // ВЦИОМ. 16.12.2020. URL: https://wciom.ru/analytical-reviews/analiticheskii-obzor/zhiznonlain-potreblenie-polzovanie-razvlechenija (дата обращения: 11.01.2021).

6. Волков Д., Гончаров С. Российский медиаландшафт - 2020: телевидение, интернет, социальные сети и мессенджеры // Вестник общественного мнения. Данные. Анализ. Дискуссии. 2020. № 1-2 (130). С. 141-147.

7. Социальные сети в России: цифры и тренды, осень 2020 // Brand Analytics. 30.11.2020. URL: https://br-analytics.ru/blog/social-media-russia-2020/ (дата обращения: 11.01.2021).

8. Types, Sources, and Claims of COVID-19 Misinformation / J. S. Brennen, F. M. Simon, P. N. Howard, R. K. Nielsen // Reuters Institute for the Study of Journalism. Oxford, 2020.13 p. URL: https://reutersinstitute.politics.ox.ac.uk/sites/default/files/2020-04/Brennen\%20\%20COVID\%2019\%20Misinformation\%20FINAL\%20\%283\%29.pdf (дата обращения: 11.01.2021).

9. Lin H., Trinkunas H. The COVID-19 infodemic: What can be done about the infectious spread of misinformation and disinformation // Bulletin of the Atomic Scientists. 10.09.2020. URL: https://thebulletin.org/2020/09/the-covid-19-infodemic-what-can-be-done-about-theinfectious-spread-of-misinformation-and-disinformation/ (дата обращения: 11.01.2021).

10. Михайленок О. М., Малышева Г. А. Роботизация социальных сетей и ее политические последствия // Власть. 2020. Том. 28. № 1. С. 85-92. DOI: https://doi.org/10.31171/vlast.v28i1.7046

11. Инфодемия: как рождаются паника и фейки во время эпидемий / Н. Петров, А. Архипова, В. Спиридонов, Б. Пейгин // Мониторинг экономической ситуации в России: тенденции и вызовы социально-экономического развития. 2020. № 8 (110). С. $70-77$.

12. Российское общество после президентских выборов-2018: запрос на перемены. Информационно-аналитический доклад. М.: ФНИСЦ РАН, 2018. 55 с.

13. Коронавирус: страх и занятость // Левада-Центр. 31.07.2020. URL: https://www.levada.ru/2020/07/31/koronavirus-strah-i-zanyatost/ (дата обращения: 11.01.2021).

14. Меры по борьбе с пандемией коронавируса // Левада-Центр. 08.06.2020. URL: https://www.levada.ru/2020/06/08/mery-po-borbe-s-pandemiej-koronavirusa/ (дата обращения: 11.01.2021).

15. Итоги 2020-го: события, люди, оценки, ожидания от 2021-го // ВЦИОМ. 22.12.2020. URL: https://wciom.ru/analytical-reviews/analiticheskii-obzor/itogi-2020-go-sobytija-ljudi-ocenkiozhidanija-ot-2021-go (дата обращения: 11.01.2021).

16. Академик PAH Михаил Горшков. COVID-19 в контексте социальной диагностики // Научная Россия. 18.04.2020. URL: https://scientificrussia.ru/articles/akademik-ran-mihailgorshkov-covid-19-v-kontekste-sotsialnoj-diagnostiki (дата обращения: 11.01.2021). 
17. Свешникова А., Соболевская А. Юмор против пандемии// к-ФOM. 21.10.2020. URL: https://covid19.fom.ru/post/yumor-protiv-pandemii (дата обращения: 11.01.2021)

18. Ц Цифровые технологии и кибербезопасность в контексте распространения COVID-19 // Счетная палата Российской Федерации. 2020. URL: https://ach.gov.ru/upload/pdf/Covid-19-digital.pdf (дата обращения: 11.01.2021).

19. Шваб К., Дэвис Н. Технологии Четвертой промышленной революции (пер. с англ.). М.: Эксмо, 2018. 320 с.

20. Чеклецов В. В. Социальная оценка вызовов цифровой реальности и моделирования развития киберфизических систем в контексте пандемии COVID-19 // Философские проблемы информационных технологий и киберпространства. 2020. № 1 (17). С. 4-15. DOI: $10.17726 /$ philIT.2020.1.1

21. Левашенко А. Д., Магомедова О. С. Риски цифровой дискриминации в условиях COVID-19 // Мониторинг экономической ситуации в России: тенденции и вызовы социальноэкономического развития. 2020. № 21 (123). С. 23-27.

22. Шнайдер Е. Как пандемия повлияла на цифровизацию индустрии культуры и искусства // Сноб. 05.10.2020. URL: https://snob.ru/entry/198547/ (дата обращения: 11.01.2021).

23. Введенская Е. В. Актуальные проблемы робоэтики // Науковедческие исследования. 2019. № 2019. C. 88-101. DOI: $10.31249 /$ scis/2019.00.06

24. Режим самоизоляции: ожидания, мотивы, оценка введенных ограничений. Аналитический доклад. // ВЦИОМ. 27.04.2020. URL: https://wciom.ru/analyticalreports/analiticheskii-doklad/rezhim-samoizolyaczii-ozhidaniya-motivy-oczenkavvedennykh-ogranichenij (дата обращения: 11.01.2021).

25. Frey C. B., Chen C., Presidente G. Democracy, Culture and Contagion: Political Regimes and Countries Responsiveness to Covid-19 // Oxford Martin School, Oxford University. 2020. 20 p. URL: https://www.oxfordmartin.ox.ac.uk/downloads/academic/Democracy-Culture-andContagion_May13.pdf (дата обращения: 11.01.2021).

26. Кросскультурный мониторинг образов инфодемии и пандемии. Может ли политический лидер выйти за пределы культурной матрицы? / А. Г. Асмолов, Г. У. Солдатова, Т. М. Малева, С. С. Сорокина, Т. Л. Алдошина // Мониторинг экономической ситуации в России: тенденции и вызовы социально-экономического развития. 2020. № 10 (112). С. $138-149$.

27. Талапина Э. В., Черешнева И. А. Применение цифровых технологий в условиях пандемии с точки зрения прав человека: аналитический обзор // Мониторинг экономической ситуации в России: тенденции и вызовы социально-экономического развития. 2020. № 12 (114). C. 5-10.

28. Глазьев С. Ю. Информационно-цифровая революция // Датчики и системы. 2018. № 1 (221). C. 4-17. 